\title{
PSYCHOPATHOLOGICAL COMORBIDITY IN MINORS WITH CONDUCT DISORDER
}

Department of Psychiatry and Hospital Pharmacy.

\section{Introduction}

Conduct Disorder is the most frequent diagnosis in patients referred from primary health care services to child psychiatry departments. Most cases with such diagnosis usually have some other co-morbid psychopathologic condition.

\section{- Objectives:}

To study the most frequent associated mental disorders in minors, who follow up in child psychiatry for Conduct Disorder.

\section{Methods}

- Retrospective descriptive study

- Data were collected from SESCAM computerised database

- A sample of 44.987 minor patients from Talavera de la Reina area was narrowed down by Conduct Disorder, and then refined the search by co-morbid mental disorders.

- A total of 200 patients were studied, with a mean age of 10 years, $60 \%$ males.

\section{Results}

In these patients the most common co-morbid mental disorders were:

\section{Co-morbid mental disorders}

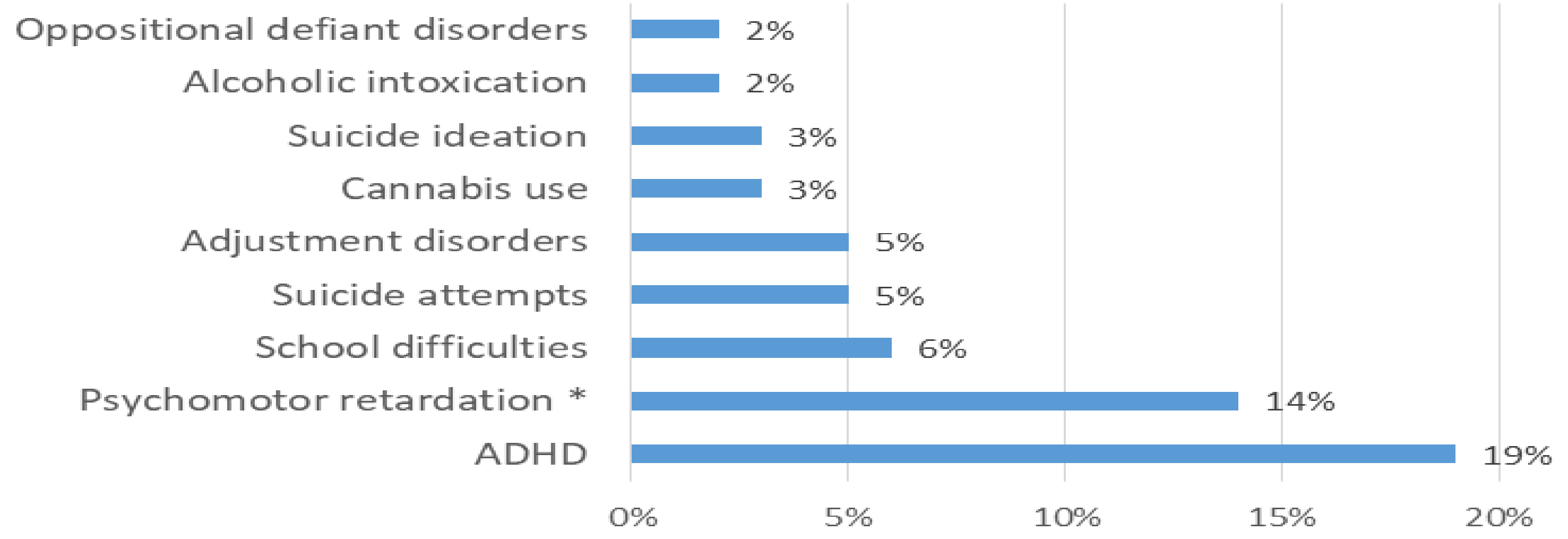

${ }^{*}$ Psychomotor Retardation/ Development delay (3\% Severe Mental Retardation, IQ less than 34).

\section{Conclusions:}

$>$ In patients meeting Conduct Disorder it is important to look into co-morbid psychopathology.

$>$ The three mental disorders most commonly associated would be: ADHD, Lagging Development and School Difficulties.

$>$ This should make us suggest cross-cutting programmes with schools, which is where we can carry out part of the treatment of such cases. 